\title{
Mixing dynamics on the inner shelf of the Ebro Delta
}

\author{
IMMA BASTIDA ${ }^{1}$, JESÚS PLANELLA ${ }^{1}$, ELENA ROGET ${ }^{1}$, JORGE GUILLÉN ${ }^{2}$, \\ PERE PUIG $^{2}$ and XAVIER SÁNCHEZ ${ }^{1}$ \\ ${ }^{1}$ Universitat de Girona, Department of Physics, Group of Environmental Physics, Campus de Montilivi, PII, \\ 17071 Girona, Catalonia, Spain. E-mail: elena.roget@udg.edu \\ ${ }^{2}$ Institut de Ciències del Mar, Marine Geology Department, CSIC, Passeig Marítim de la Barceloneta 37-49, \\ 08003 Barcelona, Catalonia, Spain.
}

\begin{abstract}
SUMMARY: Turbidity, CTD, and temperature and shear microstructure data recorded along a $25 \mathrm{~km}$ transect from 8 to 69 $\mathrm{m}$ depth across the Ebro Delta shelf (northwestern Mediterranean) are presented. The water column was stratified and prior to the campaign the regional southwest flow was measured to have superimposed diurnal and sub-inertial components. The bottom boundary layer (BBL) at all stations deeper than $20 \mathrm{~m}$ has a vertical extension of 3 to $9 \mathrm{~m}$, increasing to $12 \mathrm{~m}$ at the deeper stations and even to $14 \mathrm{~m}$ at a station at $45 \mathrm{~m}$ depth outside the studied transect. The law of the wall was identified at almost all stations with an extension ranging from $40 \%$ to $100 \%$ of that of the BBL. At some stations high dissipation rates were found in the interior of the bottom layer. The study shows the correspondence between the turbidity contents and the local mixing processes at the BBL and suggests that sub-critical reflection of internal waves could play an important role in boundary mixing. Our data also suggest that during the campaign, after two consecutive short episodes of high winds, the first baroclinic mode shifted to the second one.
\end{abstract}

Keywords: bottom boundary layer, nepheloid layer, inner shelf, turbulence, turbidity, internal waves, mixing.

\begin{abstract}
RESUMEN: Dinámica de mezcla en la plataforma continental del Ebro. - Se presentan datos de turbidez, CTD y microestructura (temperatura y cizalla) a lo largo de un transecto a través de la plataforma continental del Delta del Ebro, desde 8 a $69 \mathrm{~m}$ de profundidad, en la parte noroeste del mar Mediterráneo. La columna de agua estaba estratificada e inmediatamente antes de la campaña la corriente cerca del fondo presentaba periodicidades diarias y sub-inerciales. La extensión vertical de la capa de fondo (BBL) en las estaciones más profundas de $20 \mathrm{~m}$ varía entre 3 y 9 metros, pero alcanza los $12 \mathrm{~m}$ en la estación más profunda y es de $14 \mathrm{~m}$ en otra estación situada a $45 \mathrm{~m}$ de profundidad no incluida en el transecto. Se ha detectado la existencia de la ley de la pared en casi todas las estaciones, ocupando una extensión entre el $40 \%$ y el $100 \%$ de la BBL. En algunas estaciones la disipación aumenta en el interior de la BBL. Los datos muestran la correspondencia en la BBL entre la distribución de turbidez y los procesos físicos de mezcla locales y sugieren que la reflexión cuasi crítica de las ondas internas podría jugar un papel importante en la mezcla en el fondo. Nuestros datos tanbien sugieren que durante la campaña y después de dos cortos episodios de viento fuerte, la estructura baroclínia cambió de un primer a un segundo modo.
\end{abstract}

Palabras clave: capa de fondo, capa nefeloide, plataforma continental, turbulencia, turbidez, ondas internas, mezcla.

\section{INTRODUCTION}

During the last few decades, many studies have focused on determining the dynamics and forcing mechanisms of the processes occurring on the continental shelf by looking closely at mixing in the entire water column and in the BBL (Millot and Crepon 1981, Philips et al. 1986, Garrett 1990). It is known that periodically forced bottom boundary layers (BBLs) do not follow the classical law of the wall (Lorke et al. 2002, Perlin et al. 2005, Howard and Souza 2005) and that current shear stresses might maintain sediment in suspension or even cause resuspension of the bottom sediments (Davis et al. 1988). Complementing shearinduced turbulence (Welles et al. 2010), buoyancydriven convective mixing can be an important mechanism for the formation of well-mixed BBLs on continental shelves. Convective turbulence can be produced 
by the differential transport of stratified water masses along the shelf, which brings heavier water to the top of lighter water (Lorke et al. 2005) or by Ekman-induced downwelling (Moum et al. 2004). Other authors have referred to mechanisms such as shoaling breaking waves (Garrett and Gilbert 1988) and wave-wave interaction (Soloviev et al. 2001). Furthermore, internal wave reflection on sloping boundaries also leads to elevated levels of shear, strain, and turbulent overturns (Eriksen 1985, Thorpe 2004), which might cause intermediate nepheloid layer formation (Cacchione and Drake 1986). Critical reflection (McPhee-Shaw and Kunze 2002), wave steeping and front formation at the slope can also enhance the mixing (Thorpe 1987, 1997, Staquet and Sommeria 2002). The relevance of nearinertial internal waves on the dynamics of continental shelves has also been demonstrated (van Haren and Mass 1987, Chant 2001).

Substantial progress has been made in understanding the effect of sloping bottoms on the mixing of the stratified water column on the shelf. However, in many cases the identification of the leading mechanism and the parameterization of turbulent fluxes are still open questions. Within this context, the Ebro Delta continental shelf along the Catalan coast in the northwestern Mediterranean Sea (hereafter the Ebro shelf) has been widely studied. As a result, relevant information has been obtained on slope fronts (Font et al. 1988), shelfslope exchanges, bottom currents and resuspension (Cacchione et al. 1990, Guillen et al. 2002), internal waves (Font et al. 1990, Tintoré et al. 1995, Puig et al. 2001), and sediment fluxes (Palanques et al. 2002). From a complementary point of view, in this paper, together with standard conductivity-temperature-depth (CTD) data, we present turbulence parameters and turbidity data along one cross-slope transect of about $25 \mathrm{~km}$ across the Ebro shelf. This gives an overall perspective of the mixing processes and their relation to the sediment contents of the whole water column in the region, and more specifically in the BBL, which is studied in more detail.

The continental shelf of the study area covers an area of about $60 \mathrm{~km}$ and the coastal and offshore (i.e. continental slope) regions can be clearly distinguished (Font et al. 1988). The inner shelf is characterized by shallow waters up to $30 \mathrm{~m}$ depth, with a smooth inclination of about $0.2^{\circ}$, while the mid-shelf (30 to $60 \mathrm{~m}$ depth) has a steeper inclination of around $0.5^{\circ}$ and the outer shelf has a gentle slope with an inclination of $0.1^{\circ}$ or less (Diaz et al. 1990).

The annual mean water discharge of the Ebro River ranges from 300 to $600 \mathrm{~m}^{3} / \mathrm{s}$ and is strongly dependent on the seasonal climate. At present, the water discharge is dam-controlled and sediment discharge is around $1 \%$ of the pre-dam conditions. Consequently, delta coast evolution and sediment transport are dominated by marine processes (Guillén and Palanques 1997). The density and temperature structures of the water column are inevitably linked to the Ebro River discharge. In spring and summer, under the thermocline, there is slope water with a salinity range of between 37.5 and 38.2 , while on top of it coastal water with a salinity lower than 37.8 is generally found. A bottom nepheloid layer extends over the continental shelf and reaches its greatest concentration above the mid-shelf mud belt (Palanques and Drake 1990).

Water circulation along the Ebro shelf is dominated by a southwest coastal current, which can be modified by inertial oscillations, and shelf-slope density front instabilities, producing current reversals. However, the main southwest direction is hardly affected by local winds, achieving values of about 15 $\mathrm{cm} / \mathrm{s}$, decreasing shoreward (Font et al. 1990, Salat et al. 1992).

\section{MATERIAL AND METHODS}

\section{The field campaign}

Data presented in this paper were recorded from 18 to 20 June 2004 on board the B/O Garcia del Cid during an oceanographic cruise linked to the RESPONSE Project (Demestre et al. 2008, de Juan et al. 2009). During the cruise, microstructure data were taken using an MSS profiler equipped with precision CTD sensors, fast-response shear and temperature sensors (Prandke and Stips 1998), and a turbidity sensor (Wolk et al. 2002). The profiler had a free-falling velocity limit of $0.7 \mathrm{~m} / \mathrm{s}$ and the sampling frequency was $1024 \mathrm{~Hz}$. The lowest falling velocity acceptable for the correct functioning of the shear sensor is $0.4 \mathrm{~m} / \mathrm{s}$ (Prandke 2005), which was always reached before a depth of $2 \mathrm{~m}$. Measurements were performed twice along the same cross-shelf transect of about $24 \mathrm{~km}$ containing 11 stations, located approximately 2 or $3 \mathrm{~km}$ apart (Fig. 1). Profiling measurements were recorded twice at each station in both transects. The two sets of data along the transect will be referred to as transect 1 (T1) and transect 2 (T2). General information of the stations is included in the first three lines in Table 1. Also, two series of 15 profiles were recorded at two stations apart

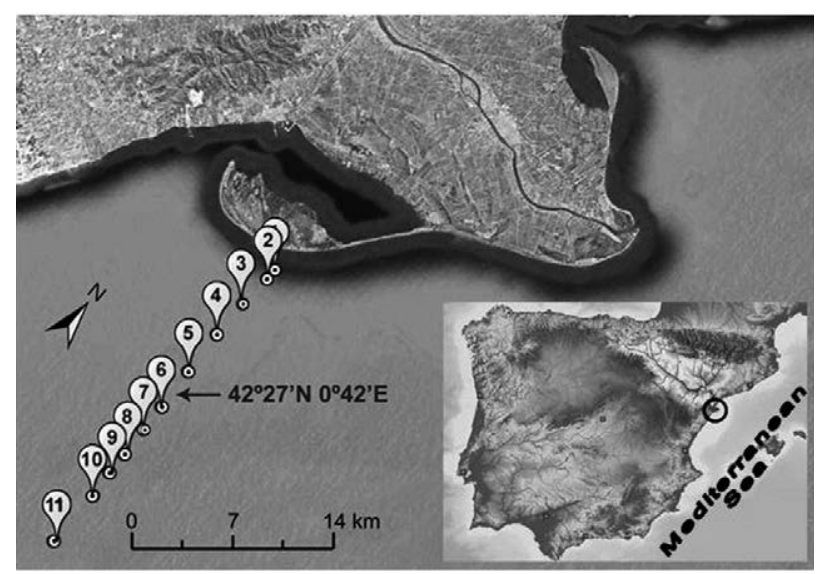

Fig. 1. - Situation of the hydrographical stations along the crossshore transect on the inner shelf south of the Ebro Delta. 
TABLE 1. - Basic information about each station including the vertical extension of the bottom boundary layer (BBL) and where the law of the wall (WL) is valid for the two transects. The cases where the dissipation rate is found to increase above a layer where the law of the wall is accomplished are indicated with the sign + .

\begin{tabular}{lcccccccccc}
\hline Stations & 2 & 3 & 4 & 5 & 6 & 7 & 8 & 9 & 10 & 11 \\
\hline Distance from St1 (m) & 770 & 3200 & 6019 & 9286 & 12468 & 14498 & 16405 & 18130 & 20222 & 14148 \\
Depth (m) & 12.7 & 20.9 & 28.6 & 39.0 & 48.3 & 53.0 & 57.5 & 61.3 & 64.0 & 68.9 \\
Angle of the slope & 0.312 & 0.193 & 0.156 & 0.182 & 0.167 & 0.133 & 0.135 & 0.126 & 0.073 & 0.071 \\
Transect 1 & & & & & & & & & \\
$\quad$ BBL extension (m) & No & $6 \mathrm{~m}$ & $7 \mathrm{~m}$ & $5 \mathrm{~m}$ & $8 \mathrm{~m}$ & $5 \mathrm{~m}$ & $5 \mathrm{~m}$ & $3 \mathrm{~m}$ & $6 \mathrm{~m}$ & $6 \mathrm{~m}$ \\
$\quad$ WL extension (m) & No & $6 \mathrm{~m}+$ & $4 \mathrm{~m}+$ & $3 \mathrm{~m}+$ & $5 \mathrm{~m}$ & $2 \mathrm{~m}+$ & $3 \mathrm{~m}+$ & No & $5 \mathrm{~m}$ & $3 \mathrm{~m}+$ \\
$\quad$ Transect 2 & $2 \mathrm{~m}$ & No & $9 \mathrm{~m}$ & $5 \mathrm{~m}$ & $8 \mathrm{~m}$ & $7 \mathrm{~m}$ & $5 \mathrm{~m}$ & $5 \mathrm{~m}$ & $9 \mathrm{~m}$ & $12 \mathrm{~m}$ \\
$\quad$ BBL extension (m) & $2 \mathrm{~m}$ & $2 \mathrm{~m}$ & No & No & $3 \mathrm{~m}+$ & No & $3 \mathrm{~m}+$ & $3 \mathrm{~m}+$ & $6 \mathrm{~m}+$ & $7 \mathrm{~m}+$ \\
$\quad$ WL extension (m) & & & & & & & & &
\end{tabular}

from the transect but very close to station $6(\mathrm{StP})$ and station $9(\mathrm{StC})$. In all cases measurements were taken down to the bottom.

When making microstructure measurements, the oceanographic ship stopped and switched off the engine to prevent the cable connecting the profiler with the ship from breaking. This practice also allowed us to obtain good turbulence data for the uppermost layer, which otherwise could have been contaminated by the ship. Due to the distance between the stations, the spatial resolution of the measurements is limited by the Nyquist wavenumber (Emery and Thomson 2001), so if there were important features with characteristic scales smaller than 4-6 km, they could be erroneously interpreted as larger-scale events.

Measurements at stations 3 to 11 for the transect T1 were taken seaward starting at about $6 \mathrm{pm}$ on 18 June and lasting about 4.25 hours, with a mean ship velocity of about $1.3 \mathrm{~m} / \mathrm{s}$. For stationary features with frequencies around the inertial frequency $(\tau=18.3 \mathrm{~h})$ or lower, the transect was recorded quickly enough to get an overall synoptic view. However, when traced features propagate, the mean ship velocity in relation to the feature to be measured should be taken into account. Note, for instance, that if the ship is moving at the same velocity as a wave and in the same direction, the wave will not be detected; but if the ship moves in the opposite direction, it will measure a wave length double the real one.

At the start of the measurements for transect $\mathrm{T} 1$ (from stations 3 to 11) there was a light southerly wind (about $3 \mathrm{~m} / \mathrm{s}$ ) becoming an easterly wind (Fig. 2). Stations 1 and 2 of the transect T1 were measured about 24 hours later, when the wind was also blowing from the south but at about double the intensity $(\sim 6 \mathrm{~m} / \mathrm{s})$ of the previous day (Fig. 2). The transect T2 was measured on 20 June landward, starting at about $6 \mathrm{pm}$ and with a cruise velocity similar to that of T1. Measurements
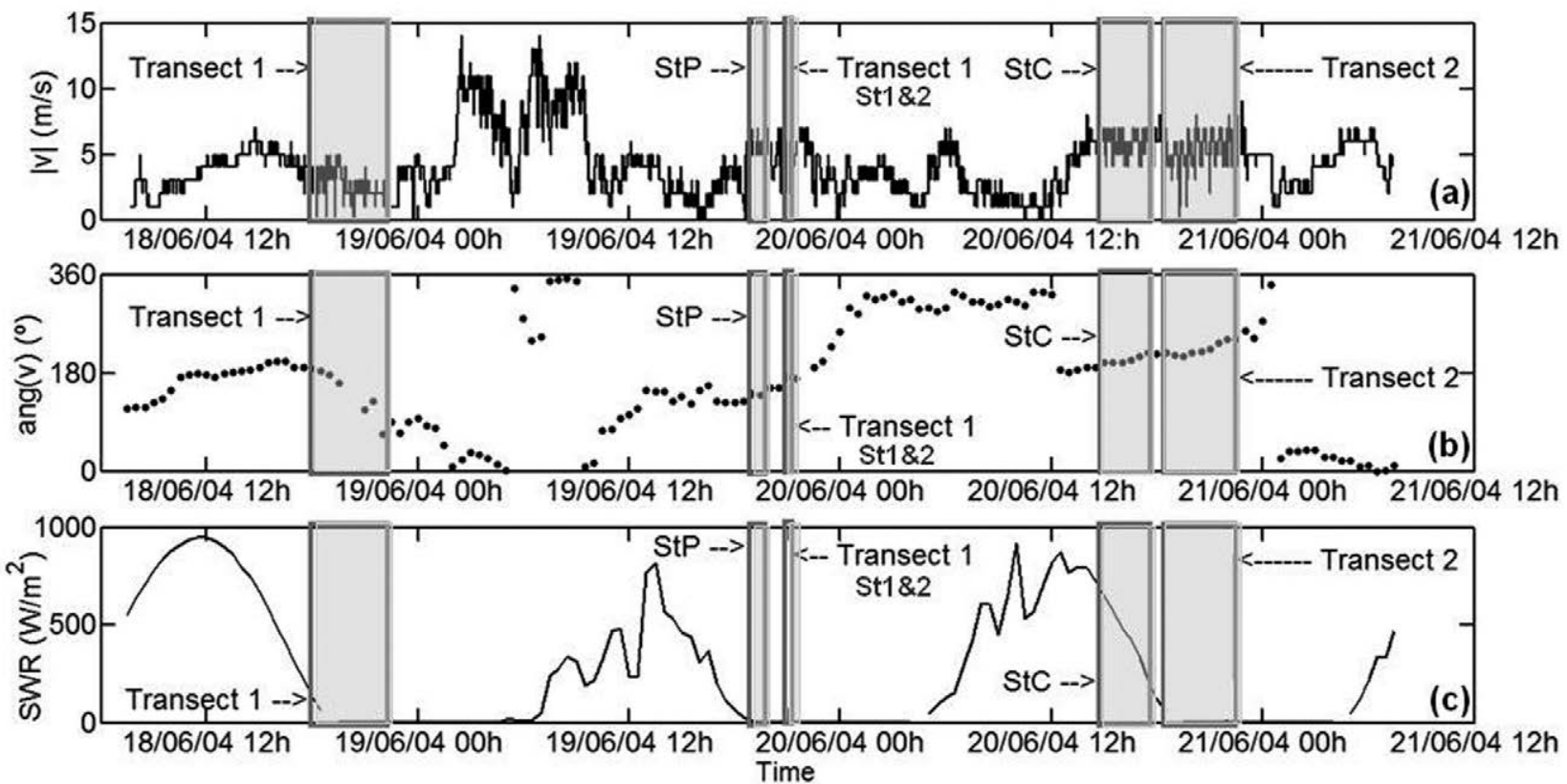

Fig. 2. - Meteorological data at the site of the campaign: (a) wind velocity (b) wind direction and (c) short-wave radiation. Time is represented on the $\mathrm{x}$ axis and labels are placed every 12 hours. Rectangular windows show the periods of time when different sets of data were recorded, i.e. transect 1, transect 2 and two stations outside the transects StC and StP. Stations 1 and 2 (St1\&2) of transect 1 are indicated apart from transect 1 as they were measured about 24 hours later than the other stations of this transect. 
along $\mathrm{T} 1$ were carried out before commercial fish trawling activity began around station 6 , while those along T2 were taken after fishing had ceased. Measurements at station StP were made for 40 minutes without anchoring the ship on the afternoon of the second day of the campaign and those at station $\mathrm{StC}$ on 20 June for one hour 40 minutes, before the measurements for transect T2 were started (Fig. 2).

Note from Figure 2 that in the intermediate period between the two transects and, more precisely, during the night and morning of 19 June, there were two episodes of high southerly winds (between 7 and $12 \mathrm{~m} / \mathrm{s}$ ), which lasted 3 and 4 hours, respectively. The sky was partially covered on 19 June and during the morning of 20 June and clear during the rest of the campaign.

During the 15 days immediately prior to the start of the campaign, velocity data were recorded every 10 minutes by an Aanderaa RCM- 9 current meter moored close to station 6 at $0.5 \mathrm{~m}$ above the bottom. There are no velocity data for the period of the campaign.

\section{Data processing and calculation of turbulent variables}

Standard processing of the CTD data was performed. A recursive filter was applied to the conductivity signal to adjust the different time responses of the CT and then salinity, density and Brunt-Väisäla frequency $\left(N^{2}\right)$ were calculated following the EOS-80 seawater equation recommended by UNESCO in 1981 (Fofonoff and Millard 1983).

After the campaign the turbidity sensor was re-calibrated to obtain the suspended sediment concentration using samples taken simultaneously with microstructure measurements at $50 \mathrm{~cm}$ above the bottom following Sanchez and Roget (2006). Linear correlation between the turbidity signal and the measured solid contents of samples recorded at the same place and depth was found to be $T U R(\mathrm{mg} / \mathrm{l})=0.42 \times T U R(\mathrm{ppm})-0.46$ with $r^{2}=0.92$. This equation was used to correct density profiles, taking into account the particles in suspension to be sure that unstable conditions observed just above the bottom were not balanced by sediment contents. The correction did not create any further instability above the bottom and only slightly modified the stratification.

The microstructure data were denoised and the rate of dissipation of the turbulent kinetic energy $(\varepsilon)$ was evaluated by fitting the experimental small-scale shear spectra for a one-metre segment of data to the analytical approximation of the transversal 1D Panchev and Kesich (1969) shear spectrum given by Roget et al. (2006).

Microstructure temperature was used to determine turbulent scales. Thorpe (1977) proposed reordering a measured vertical mixed density profile into a monotonic stable profile and calculating the root mean square (Thorpe scale) of the vertical displacements (Thorpe displacements) to characterize the vertical size of overturns. In cases in which temperature and salinity background profiles contribute to column stability, the Thorpe scale based on either temperature or salinity will make sense as a characteristic measure of the overturns if the same results are given by either microstructure temperature or salinity data (Alford and Pinkel 2000, Stansfield et al. 2001). This being the case at stations $\mathrm{StP}$ and $\mathrm{StC}$, we used microstructure temperature data recorded at those locations to determine the turbulent scales after wavelet denoising of the signal (Piera et al. 2002).

The buoyancy Reynolds number, $R e_{b}=\varepsilon / v N^{2}$ (where $v$ is the molecular kinetic viscosity), was calculated to evaluate the state of the turbulence (Gibson 1980). Fully developed turbulence requires buoyancy Reynolds numbers after a certain threshold above 15, but the exact value varies depending on the authors (Stillinger et al. 1983, Gargett et al. 1984, Lozovatsky et al. 2006). Note that $R e_{b}$ will vary similar to the diffusivity according to the Osborn (1980) parameterization $K_{b}=\gamma$ $\left(\varepsilon / N^{2}\right)$ if $\gamma$ can be considered as a constant ( $v$ varies very little depending on the temperature). The values of the so-called mixing efficiency $\gamma$ have been widely discussed (see Roget et al. 2006 for a short overview) but for well-developed turbulent flows it is usually taken as $\gamma=0.2$.

\section{Hydrodynamic diagram analysis}

Based on the Thorpe scale, $L_{T h}$, the overturn Froude $F r_{T}=\left(\varepsilon / N^{3} L_{T h}^{2}\right)^{1 / 3}$ and Reynolds numbers $\operatorname{Re}_{T}=\left(\varepsilon^{1 / 3} L_{T h}^{4 / 3} / v\right)$ were calculated for vertical segments of 1-m depth, and the state of the turbulence of 1-m segments within the BBL was characterized according to the hydrodynamic diagram proposed by Ivey and Imberger (1991) (see example in Figure 11). When the small-scale Froude number (Imberger and Boashash, 1986) is introduced as $F r_{\gamma}=\left(\varepsilon / v N^{2}\right)^{1 / 2}$, the overturn and small-scale Froude numbers are connected by the overturn Reynolds number $\left(F r_{T}=\left(R e_{T}\right)^{-1 / 2} F r_{\gamma}\right)$ so that specification of $F r_{T}$ and $R e_{T}$ is sufficient to characterize the turbulence. As is known, the $R e_{T}$ number is defined as the ratio of inertial forces to viscous forces, the $F r_{T}$ number as the ratio of inertia to buoyancy, and $F r_{\gamma}$ as the ratio of viscosity to buoyancy. Because $N^{2} L^{2}$ can be interpreted as the potential energy per unit mass and $N$ the gravitational adjustment time scale, the $F r_{T}$ number can also be interpreted as the ratio between the dissipation of the turbulent kinetic energy and the maximum rate of release of potential energy from the density profiles, so if $F r_{T}>1$, dissipation must be balanced by either local shear production of turbulent kinetic energy or by importation of turbulent kinetic energy. If $F r_{T}<1$, the potential energy of unstable portions in the water column, due to internal wave instabilities or intrusions, can balance the dissipation of the kinetic energy fluctuations. On the other hand, Ivey and Nokes (1989) consider that viscosity suppresses the turbulence when $R e_{T}=15$, so overturning is suppressed by the combined action of buoyancy and viscosity when the value of $F r_{\gamma} \approx 15^{1 / 2}=3.9$. Accordingly, in the hydrodynamic 
diagram fluxes in the segments located on the left hand side of the line $R e_{T}=15$ and below $F r_{\gamma}=3.9$ are expected to be negligible.

With $b$ as the buoyancy flux and $m$ as the net available mechanical energy, Ivey and Imberger (1991) showed that the generalized flux Richardson number $R_{f}=b / m$ and hence $\gamma=b / \varepsilon=\left(R_{f} / 1-R_{f}\right)$ vary greatly with $F r_{T}$ and peak for data located closely along the line $F_{r T}=1$ on the hydrodynamic diagram, when $\gamma=0.2$. On the hydrodynamic diagram the region where $R_{f}$ is expected to be larger than 0.15 is shadowed (see Figure 11).

\section{RESULTS}

\section{Mean flow before the campaign}

The progressive vector of the velocity of the current, recorded at $0.5 \mathrm{~m}$ above bottom prior to the campaign, is presented in Figure 3a. A net southwest flow was predominant but temporal flow reversals were also observed together with very clear clockwise gyres of about $1500 \mathrm{~m}$. During the 3.5 days before our campaign the mean velocity above bottom was $5.0 \pm 1.7$ $\mathrm{cm} / \mathrm{s}$, with amplitudes of up to $9.5 \mathrm{~cm} / \mathrm{s}$.

The main components of the velocity data can also be observed from their rotational spectra (Gonella 1972). The spectra are presented in Figure $3 b$, where $S^{+}$

a)

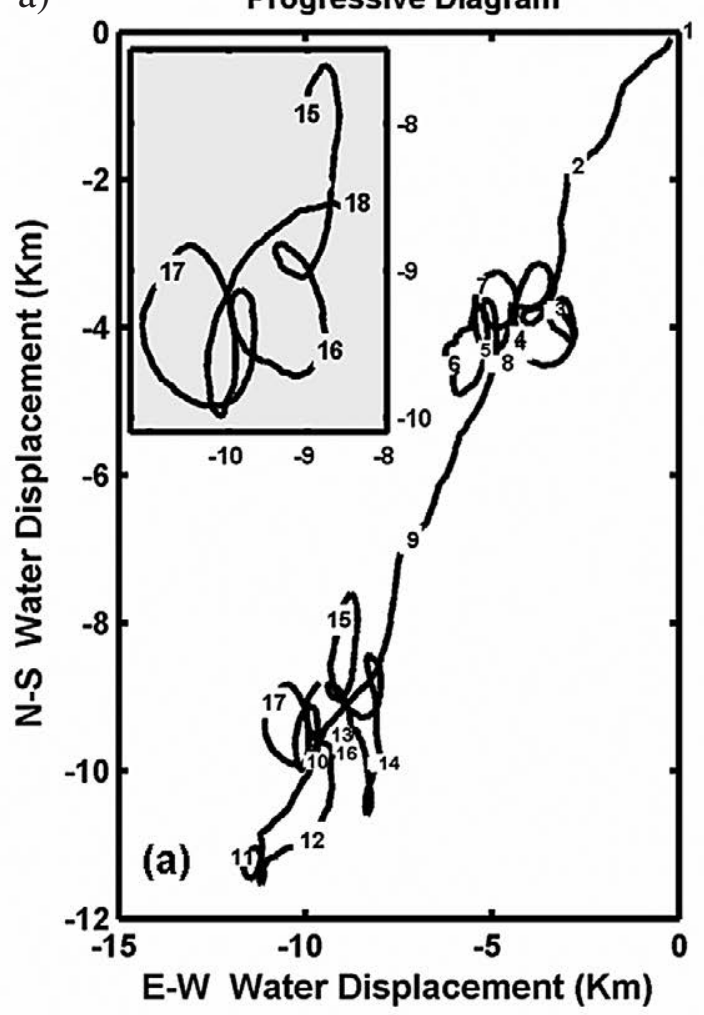

stands for the spectral density of the cyclonic components and $\mathrm{S}^{-}$for the spectral density of the anticyclonic components. Dotted lines stand for a quasi-inertial component (QI) related to the clockwise circles observed in Figure $3 \mathrm{a}$ and for the semidiurnal and quarterly diurnal tidal components, which usually appear in coastal areas in this type of analysis (Fernandes et al. 1993). More precisely, the QI peak is observed around $0.06 \mathrm{cph}$, which corresponds to $16.6 \mathrm{~h}$, lower than the local inertial frequency of $18.3 \mathrm{~h}$.

\section{Background stratification}

The contour plots of temperature and salinity for both transects are presented in Figure 4. For the whole transect, the temperature decreases towards the bottom from above $23^{\circ}$ to $14^{\circ}$ and salinity increases from about 37.3 (36.8 closer to the coast) to 38.1. In general, the isotherms and the isohalines are fairly horizontal. However, in transect $\mathrm{T} 1$ at a distance of $20 \mathrm{~km}$ from the shore and at a depth of about $40 \mathrm{~m}$ it is observed that the isotherms deepen by about $10 \mathrm{~m}$ from the horizontal position in less than $2 \mathrm{~km}$, and in the same region the isohalines rise by about $10 \mathrm{~m}$. The length scale of the event in the contour plots is about $5 \mathrm{~km}$. However, as will be explained below, in this region the isopycnals look parallel and almost horizontal (see Figs. 5c and

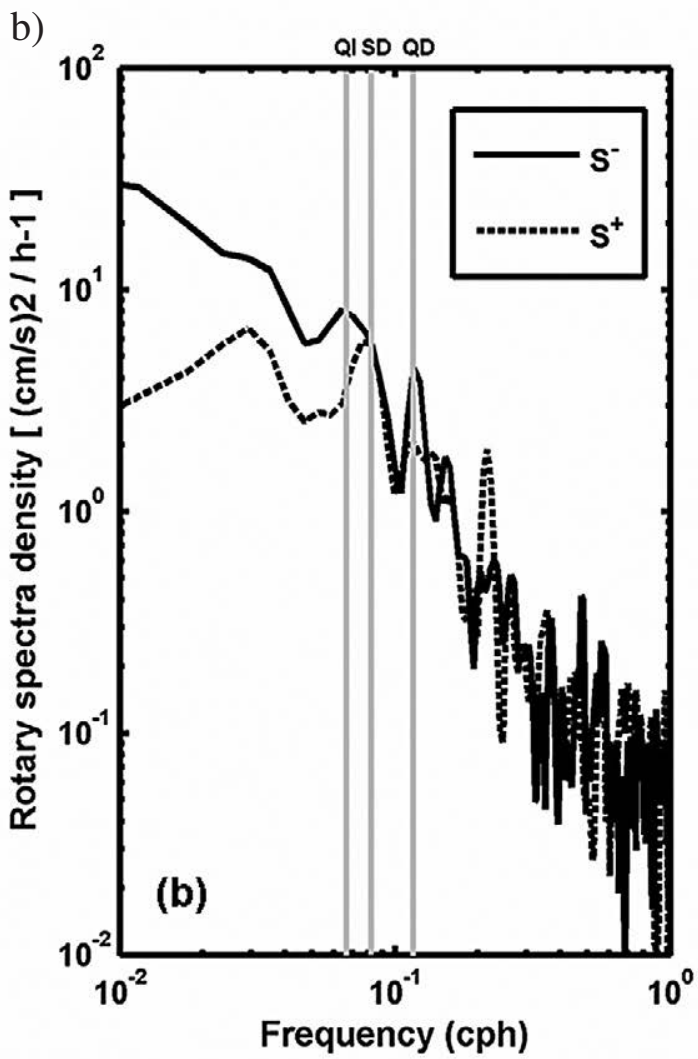

Fig. 3. - (a) Progressive vector diagram of the velocity recorded $0.5 \mathrm{~m}$ above the bottom from 1 to 17 June (labels indicates the beginning of each day). Mean circulation is towards the SW. The days before transect measurements are enlarged in the upper box. (b) Rotational spectra of the velocity data. Quasi-inertial (QI), semidiurnal (SD) and quaterly diurnal (QD) frequencies are shown in dashed vertical lines. Inertial frequency for this location was $5.5 \cdot 10-2 \mathrm{cph}(18.3 \mathrm{~h})$ while the observed quasi-inertial frequency was $0.06 \mathrm{cph}(16.6 \mathrm{~h})$ 

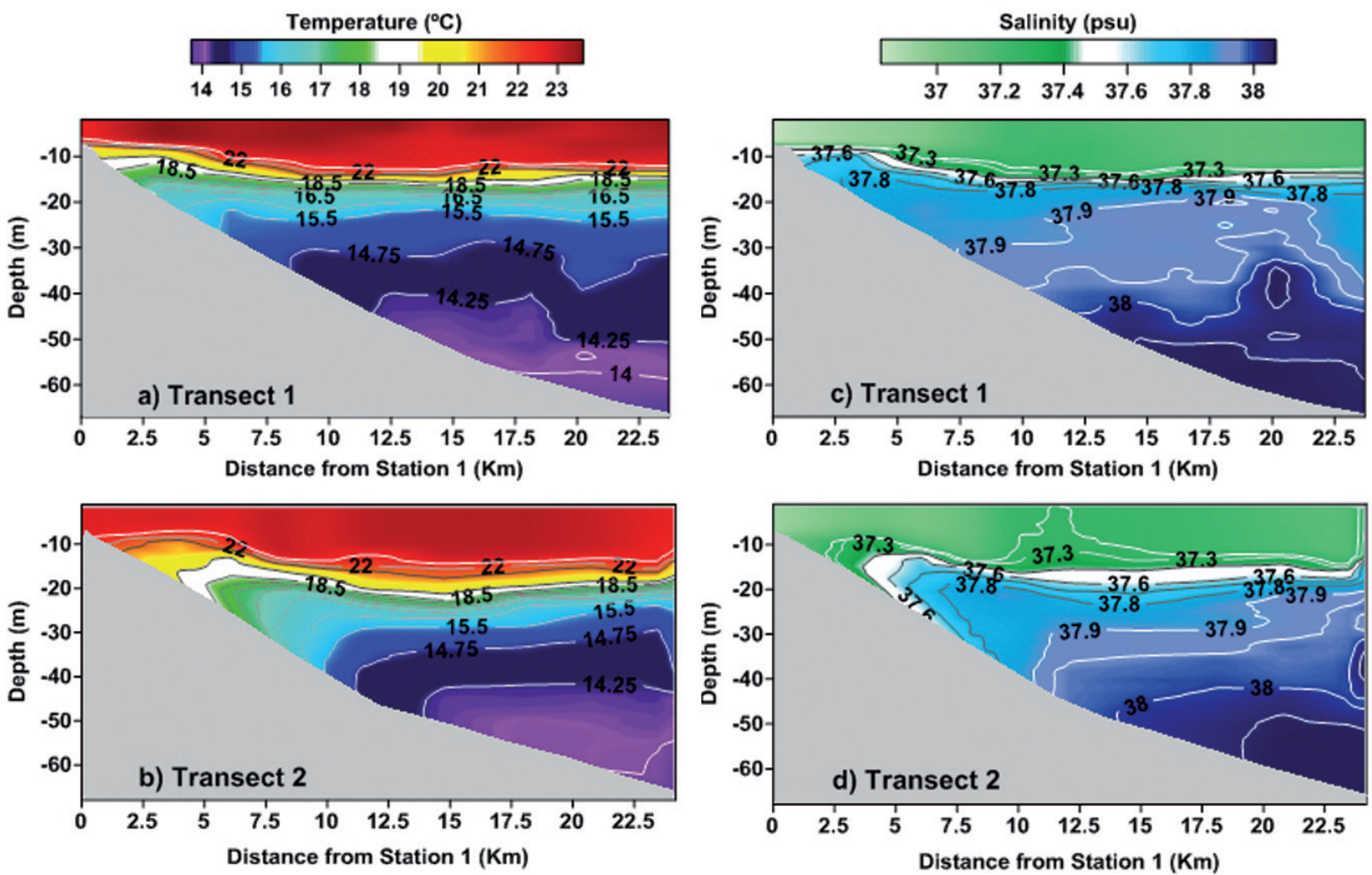

Fig. 4. - (a, b) Temperature and (c, d) salinity field measured along transects 1 and 2 , respectively. Lines on the plots are the isotherms and the isohaline curves.
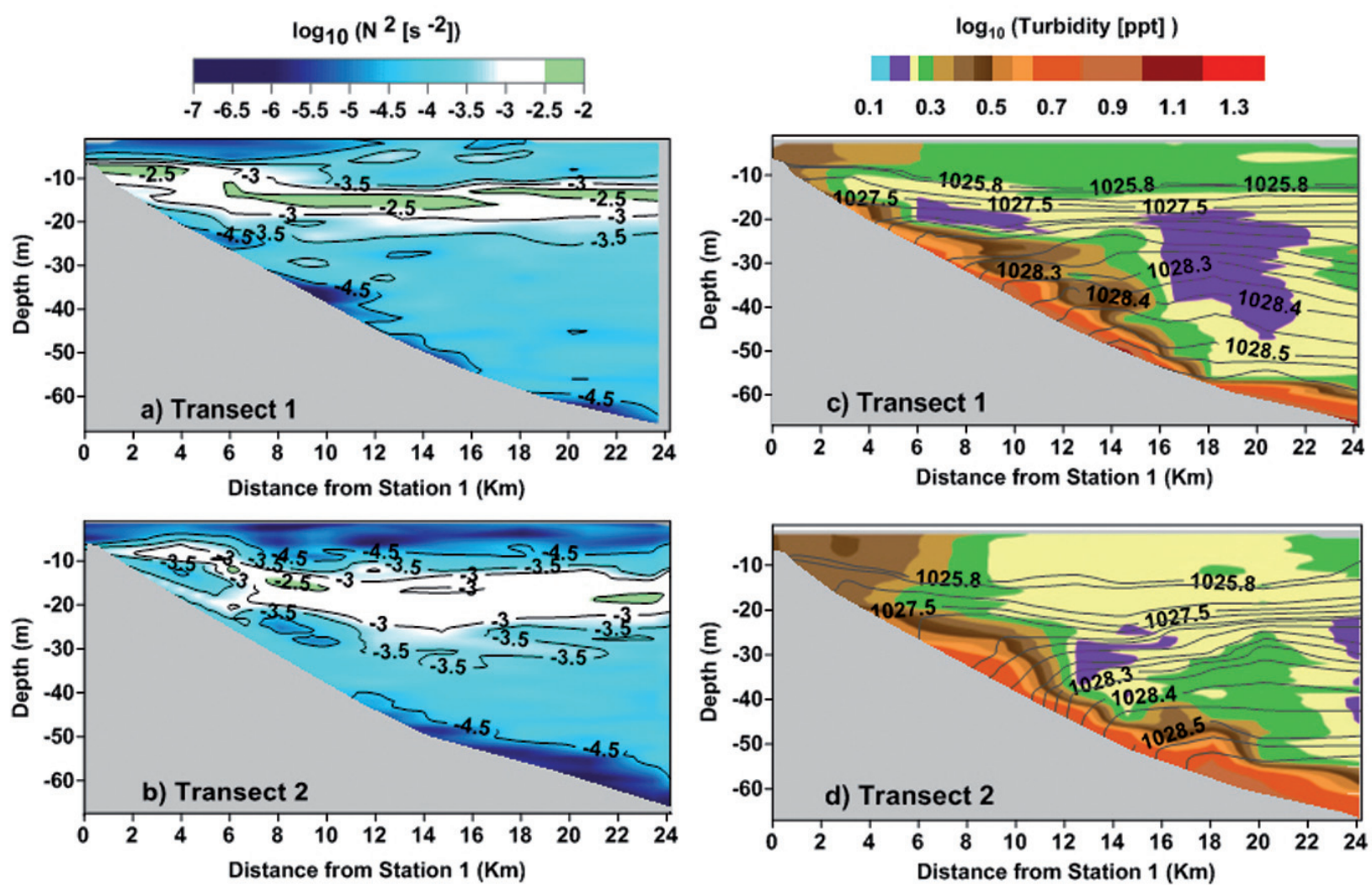

Fig. 5. - Contour plots of $(\mathrm{a}, \mathrm{b}) N^{2}$ and (c, d) Turbidity for transects 1 and 2, respectively. The isopycnal lines (in $\left.\mathrm{kg} / \mathrm{m}^{3}\right)$ have been superimposed on the turbidity plots. 


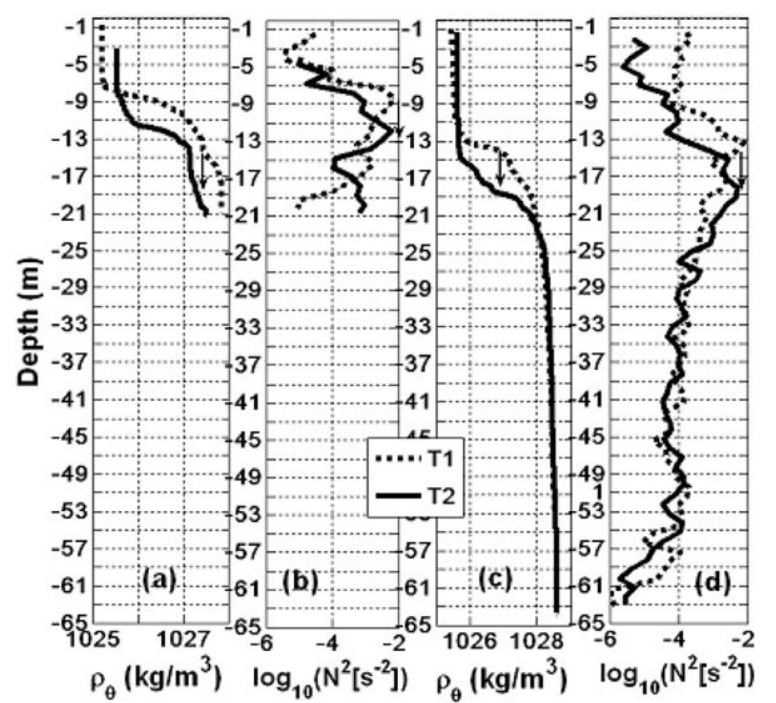

Fig. 6. - Profiles of $(\mathrm{a}, \mathrm{c})$ potential density and $(\mathrm{b}, \mathrm{d}) N^{2}$ measured along transects 1 (T1) and 2 (T2) at stations $3(\mathrm{a}, \mathrm{b})$ and 9 (c,d).

7a), suggesting the existence of either an internal flow or a remaining structure from a previous overturn when deeper, saltier and cooler water rose and mixed with shallower, fresher and warmer water. Also in transect $\mathrm{T} 2$, at a distance of $5 \mathrm{~km}$ from the shore and at a depth of about $20 \mathrm{~m}$, the water immediately above the bottom is fresher and warmer than a few metres above. The data were checked to make sure that this pattern is not related to interpolation artefacts.

Contour plots of the $N^{2}$ for the two transects, T1 and T2, are presented in Figure 5. As observed during the campaign, there was a highly stratified pycnocline where $N^{2}$ was as large as $10^{-2.5} \mathrm{~s}^{-2}$. The upper surface layer in both transects was fairly homogeneous, with $N^{2}$ smaller in T1 than in T2. Comparing the two transects, it is observed that the stratification at the pycnocline is higher and more localized in T1 than in T2, where values of $N^{2}>10^{-2.5} \mathrm{~s}^{-2}$ are rarer. The vertical extension of the highest stratified region at the pycnocline is greater in T2 than in T1 (see, for instance, the regions where $N^{2}>10^{-3} \mathrm{~s}^{-2}$ ). The mean stratification in the interior of the water column can be characterized by $N^{2} \sim 10^{-4} \mathrm{~s}^{-2}$ in both transects and, also in both of them, the stratification above the bottom diminishes below $10^{-4.5} \mathrm{~s}^{-2}$ in many places, sometimes reaching values as low as $10^{-6.5} \mathrm{~s}^{-2}$.

In Figures 5c,d the isopycnals for both transects are presented together with the turbidity contour plots. In both transects high turbidity is observed several metres above the bottom and at the upper surface layer along the first six kilometres closer to the river mouth. Offshore, the upper surface layer is much clearer although slightly more turbid in T1 than in T2. On the other hand, the mid-water column is slightly clearer in T1 than in T2. In both transects values greater than $10 \mathrm{ppt}$ are observed at several locations immediately above the bottom. Note that in T1 such locations correlate highly with the areas where $N^{2}$ is smaller, suggesting that the mixing could be related to sediment resuspen-
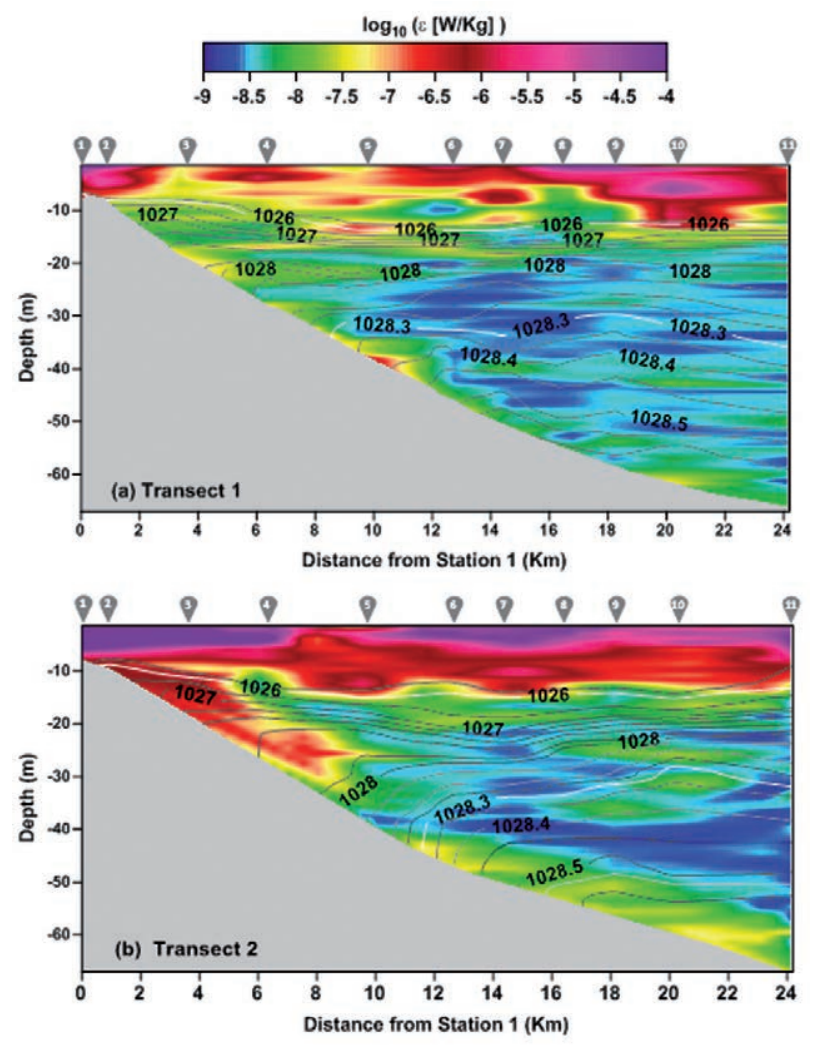

Fig. 7. - Contour plots of the turbulent kinetic energy dissipation rate with superimposed isopycnal lines (in $\mathrm{kg} / \mathrm{m}^{3}$ ) for (a) transect 1 and (b) transect 2. Numbers on the surface indicate the measuring stations.

sion. This is also true for T2, although one might have thought that this would not be the case at about $40 \mathrm{~m}$ depth. At this location turbidity above the bottom is very high but $N^{2}$ is not observed to be lower than the bulk stratification in the interior of the water column. Although $N^{2}$ is decreasing above the bottom, it is not enough to be observed in the figure.

From a perspective other than the one in Figure 5, the depths where $N^{2}$ is maximum can be observed in more detail in Figure 6, where the profiles of the potential density, $\rho_{\theta}$, and of $N^{2}$, at a shallow (st. 3) and at a deep (st. 9) station placed along the transect, have been represented for T1 and T2. As can be observed, at both stations either the basis of the homogeneous upper surface layer or the maximum of $N^{2}$ have deepened by about $3 \mathrm{~m}$ from $\mathrm{T} 1$ to T2, which represents a mean deepening of about $1.5 \mathrm{~m} /$ day that can be observed along the whole transect in Figure 5.

\section{Dissipation rate of the turbulent kinetic energy}

The contour plots of the rate of dissipation of the turbulent kinetic energy, $\varepsilon$, along $\mathrm{T} 1$ and $\mathrm{T} 2$ are presented in Figure 7. In both transects high dissipation rates are observed in the upper mixed layer and in the BBLs. Turbulent activity at the upper layer is higher in the second transect than in the first one, as is to be expected because of higher wind speeds (Fig. 2). 

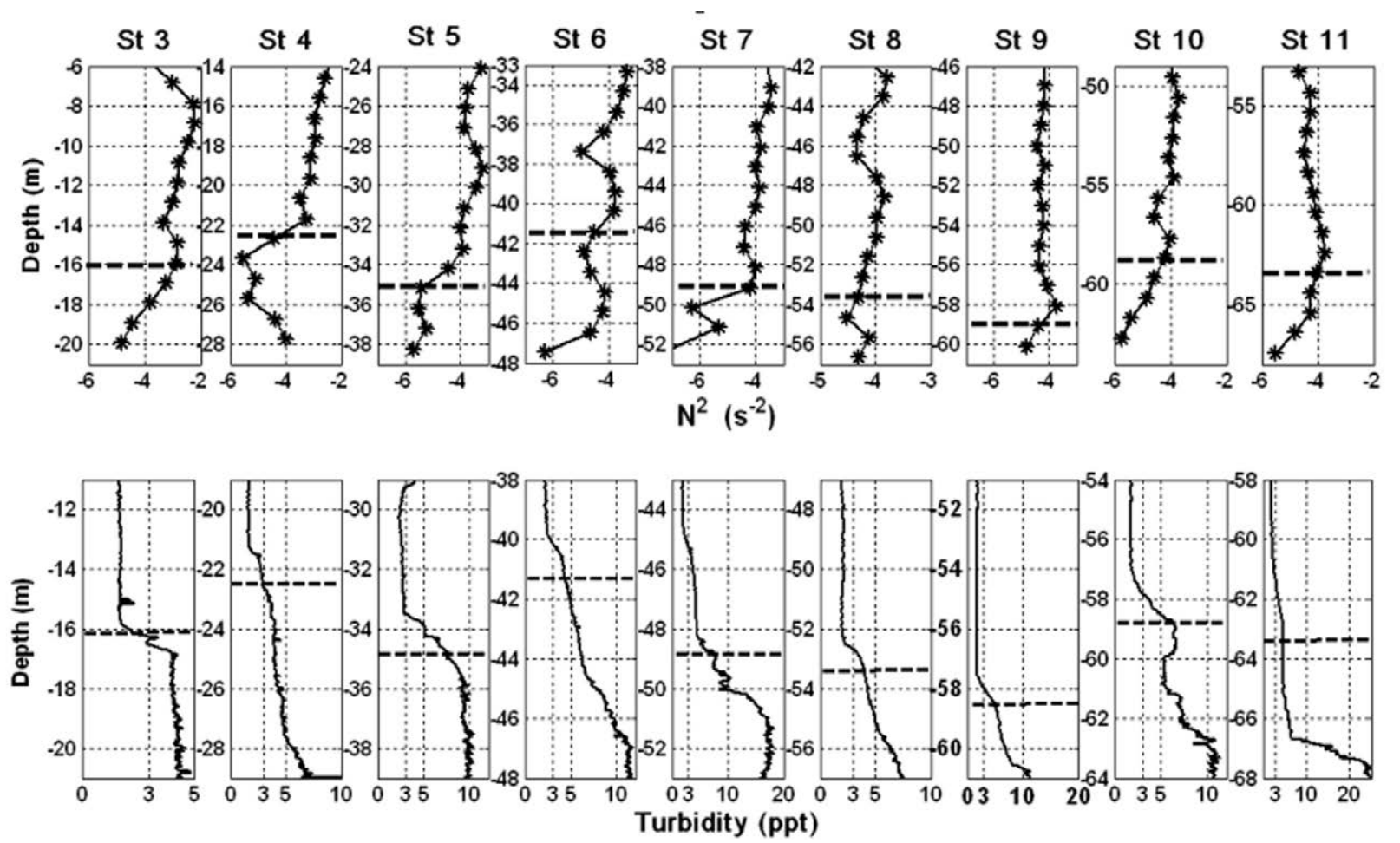

Fig. 8. - Profiles of $N^{2}$ at $15 \mathrm{~m}$ above the bottom (upper panels) and turbidity at $10 \mathrm{~m}$ above the bottom (lower panels) from stations 3 to 11 along transect T1. Horizontal lines indicate the location of the upper interface of the bottom boundary layer.

Patchy areas with dissipation rates larger than $10^{-8}$ $\mathrm{W} / \mathrm{kg}$ are observed in the interior of the water column in both figures. The data were checked to make sure that patches are not related to interpolation artefacts or to bad adjustments of the small-scale shear spectra to the Panchev-Kesich model.

In both transects, the relatively high dissipation rates observed above the bottom appear in disconnected regions of variable vertical extension that do not coincide exactly in the two transects. Note that background hydrodynamics could have changed from one transect to the other, but the intermittent spatial and temporal character of turbulence and the fact that profiling measurements can only provide snapshots should also be kept in mind.

A comparison of Figures 5c,d and Figure 7 shows how often turbidity contents above the bottom closely reflect the turbulence activity. This is the case, for instance, at a distance of $10 \mathrm{~km}$ and $20 \mathrm{~km}$ from the coast in transect T1. However, high turbidity observed $8 \mathrm{~km}$ from the coast in transect T2 does not coincide with a high dissipation rate. As commented above with regard to Figure 5, at this station the stratification above the bottom is only slightly lower than that of the interior stratification.

\section{The bottom boundary layer}

Although there is no single criterion for identifying the BBL, which is the turbulent mixed layer that develops as near-bottom currents flow over the sea floor, its vertical extension can be determined automatically after an empirical selection of appropriate variables and thresholds (Moum et al. 2004). Low stratification $\left(N^{2}\right)$, high dissipation $(\varepsilon)$ and high turbidity $(T U R)$ above the bottom can be observed in Figures 5 and 7 at almost all the stations and this is especially true for stations deeper than $40 \mathrm{~m}$ in transect T2, where a BBL can be identified at first sight on the $N^{2}, T U R$ and $\varepsilon$ plots. For shallow stations of T2 and for T1 the isolines chosen in Figures 5 and 7 for a better discussion of the whole transect do not allow the BBL to be seen although it always existed.

After detailed inspection of the data, we established $N^{2}<10^{-4} \mathrm{~s}^{-2}$ as the criterion for determining the vertical extension of the BBL at the stations with a total depth $H>25 \mathrm{~m}$. At shallower stations we observed a turbid homogeneous layer above the bottom where dissipation rates are high but where $N^{2}$, although below $10^{-4} \mathrm{~s}^{-2}$ above the bottom, increases to values higher than $10^{-4} \mathrm{~s}^{-2}$ at the upper interface of the turbidity layer. Considering the availability of sediments to be resuspended in the area and the fact that lower stratification above the bottom always coincides with high turbidity, we chose turbidity as a second criterion for determining the vertical extension of the BBL. Maximum turbidity, $T U R_{\max }$, observed above the bottom at different stations ranged from 4 to 20, so its threshold was chosen as $3 \pm 0.1 T U R_{\max }$. We rejected the rate of dissipation of the turbulent kinetic energy, $\varepsilon$, as a leading parameter because within the BBL it does not vary monotonously as it departs from 

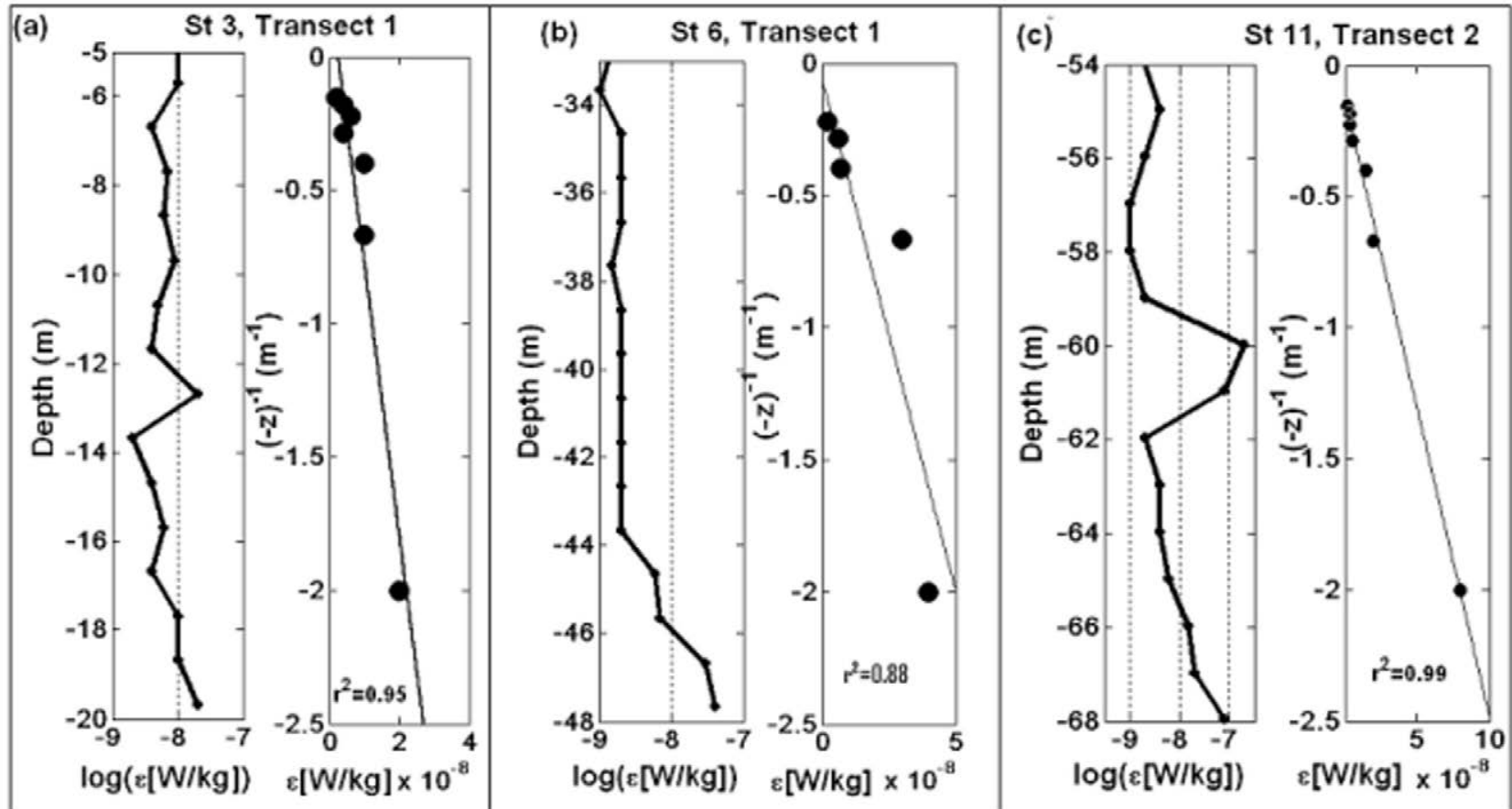

Fig. 9. - Dissipation profiles above the bottom and the corresponding fitting to the law of the wall for (a) station 3 and (b) station 6 of transect 1 and (c) station 11 of transect 2. $\mathrm{z}$ is the distance from the bottom and the depth from the surface.

the bottom, so a threshold value could not be identified. Summarizing, we determined the extension of the BBL based on the turbidity and $N^{2}$ so that in the BBL, TUR $>3 \pm 0.1 T U R_{\max }$ and either $N^{2}<10^{-4} \mathrm{~s}^{-2}$ for the whole layer or $N^{2}>10^{-4} \mathrm{~s}^{-2}$ at the upper interface of the BBL and it drecreases monotonously towards the bottom where $N^{2}<10^{-4} \mathrm{~s}^{-2}$.

In Figure 8 the profiles of $N^{2}$ (upper panels) and TUR (lower panels) for 15 and $10 \mathrm{~m}$ above the bottom, respectively, are shown for all stations of transect $\mathrm{T} 1$ deeper than $20 \mathrm{~m}$. Horizontal lines indicate the depth where the upper interface of the BBL was identified according to the thresholds discussed in this section. The same procedure was used for transect T2. Note that because $N^{2}$ is computed every metre, the location of the upper interface of the BBL cannot be determined with a better resolution. Results for both transects are summarized in Table 1, lines 5 (transect 1 ) and 7 (transect 2).

In Table 1 it can be observed that the mean vertical extension of the BBL at the stations deeper than $20 \mathrm{~m}$ varies between 3 and $9 \mathrm{~m}$. For T2, a considerably higher extension of the BBL is observed at station 11 , which could be due to a slightly different position of the ship during measurements. Although we attempted to be in the same position, measurements show that the total depth of the site varied slightly in the two transects. Based on Table 1, the mean extension of the BBL for stations deeper than $20 \mathrm{~m}$ is $5.7 \pm 1.4 \mathrm{~m}$ for $\mathrm{T} 1$ and $6.8 \pm 1.9 \mathrm{~m}$ for $\mathrm{T} 2$, without considering the last station, and $7.5 \pm 2.5 \mathrm{~m}$ considering it.

\section{Near-bottom mixing}

Mixing above the bottom layer has traditionally been related to shear-induced turbulence. In this case, assuming a logarithmic universal profile above the bottom and a quasi-steady state between production and dissipation of turbulent kinetic energy leads to the law-of-the-wall dissipation profile, which predicts that $\varepsilon$ decreases inversely to the distance from the bottom, $z$, according to equation $\varepsilon=u_{* b}{ }^{3} / k z$, where $k$ is the von Kármán constant and $u_{* b}$ the friction velocity at the bottom (Kundu 1990). At most of the stations our measurements showed that the law of the wall is valid for at least a few metres above the bottom although usually less than the vertical extension of the BBL. Several examples of $\varepsilon$ profiles and the corresponding fit to the law of the wall are presented in Figure 9.

However, data can deviate significantly from this model because of non-stationary flows. Validity and the extension of the law of the wall were checked for all stations in both transects and compared with the extension of the BBL. The percentage of the depth of the BBL where the law of the wall could be fitted ranged from $40 \%$ to $100 \%$. The results are included in Table 1 in lines 5 (transect 1) and 7 (transect 2). Note in Table 1 that the stations where the law of the wall was not observed are not the same in the two transects. In some cases, a few metres above the bottom and just above the depth down to which the law of the wall is observed, the dissipation rates are found to increase (Fig. 9a,c). These cases are indicated in Table 1 with the sign + next to the extension of the law of the wall. 


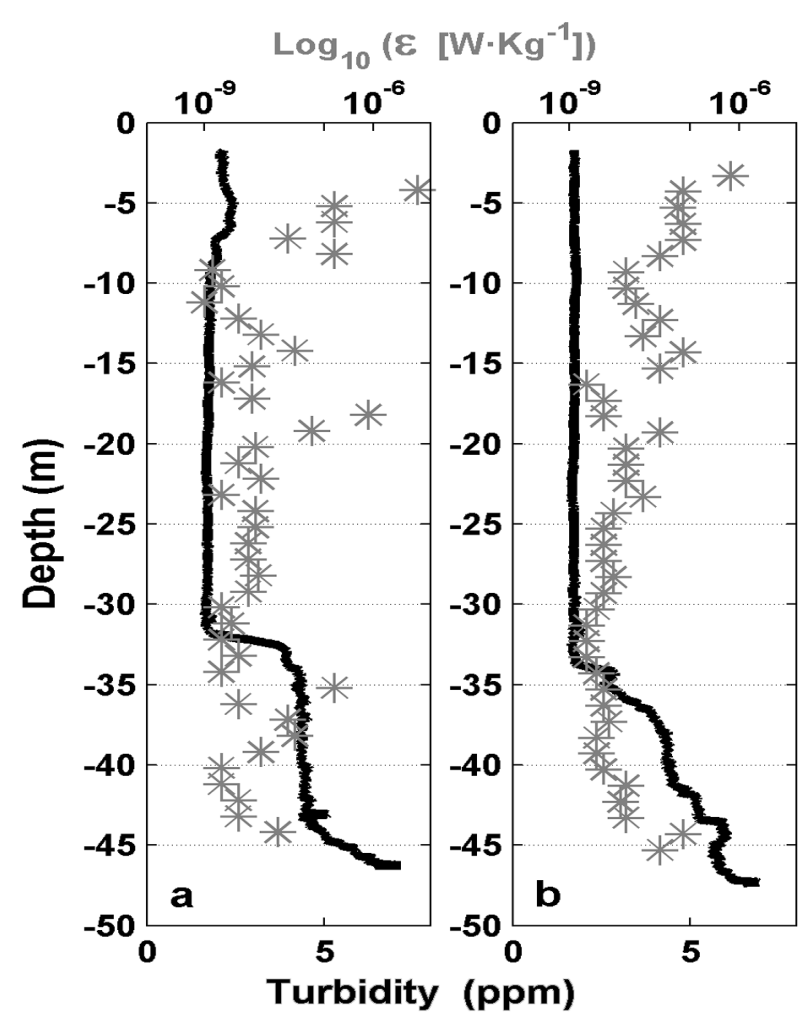

Fig. 10. - Two different characteristic profiles of turbidity and the turbulent kinetic energy dissipation rate, $\varepsilon$, measured at station StP on the 19 June in the evening.

With the idea of studying the local variability of the turbulence at the BBL, we focused on the two series of 15 profiles recorded at stations StP and StC (see Material and Methods section). For 8 profiles out of the 15 measured at StP for 40 minutes, the turbidity layer was almost homogeneous with an extension of about $14 \mathrm{~m}$ and for 7 of these 8 profiles the dissipation rate reached a maximum far $(>3 \mathrm{~m})$ from the bottom. An example of the latter type of profile is provided in Figure $10 \mathrm{a}$, where it can be observed that the dissipation rates between 35 and $39 \mathrm{~m}$ depth are higher than at $40 \mathrm{~m}$ and the turbidity between 35 and $44 \mathrm{~m}$ depth is almost

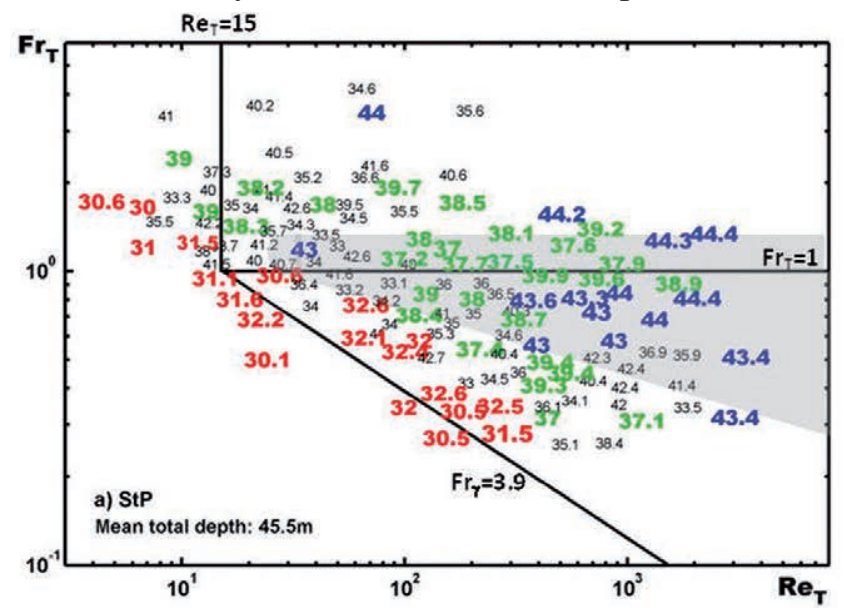

constant. Figure $10 \mathrm{~b}$ presents an example of the above 7 seven profiles where the turbidity at the BBL was not homogeneous and the dissipation rate decreased monotonously away from the bottom for more than $10 \mathrm{~m}$. In all the cases, the highest turbidity is found immediately above the bottom. Further analysis of the profiles shows that the total depth of the first type of profiles (Fig. 10a) was always slightly smaller than the total depth of the second type (Fig. 10b), indicating that the ship was drifting. Accordingly, Figure 10 illustrates the high spatial variability of turbulent activity which, from another perspective, was also commented on with regard to Figure 7.

A similar analysis performed with the other series of 15 profiles recorded at $\mathrm{StC}$ for 1 hour 40 minutes showed that for all casts turbidity at the BBL was monotonously decreasing upwards from the bottom and in the interior of the turbid BBL the dissipation rates were never observed to increase. As in StP, during these measurements the ship was not anchored.

For the whole set of measurements at stations StP and $\mathrm{StC}$ the state of turbulence at the bottom turbid layer was analysed using a hydrodynamic diagram (see Material and Methods section). The results are shown in Figure 11, where the numbers on the plots indicate the depth above the bottom of the 1-m segments. Mean depth is $45.5 \mathrm{~m}$ at $\mathrm{StP}$ and $60.4 \mathrm{~m}$ at $\mathrm{StC}$. At both StP (Fig. 11a) and StC (Fig. 11b) the majority of segments belonging to the upper part of the BBL (see red numbers in Figure 11) are found along $F_{\gamma}=3.9$, where turbulence is suppressed. This indicates that during our campaign vertical fluxes outside the turbid BBL were of no relevance. On the other hand, for both stations, the segments located immediately above the bottom (see blue numbers in Figure 11) are found at both sides of the line $\mathrm{Fr}_{T}=1$ and the majority of them $(90 \%$ at $\mathrm{StP}$ and $55 \%$ at $\mathrm{StC}$ ) within the shaded area where mixing efficiency $\gamma>0.15$. At StC (Fig. 11b) there are also a considerable number of blue segments above the shaded area, indicating high dissipation at the smallest scales, but it does not contribute much to the vertical

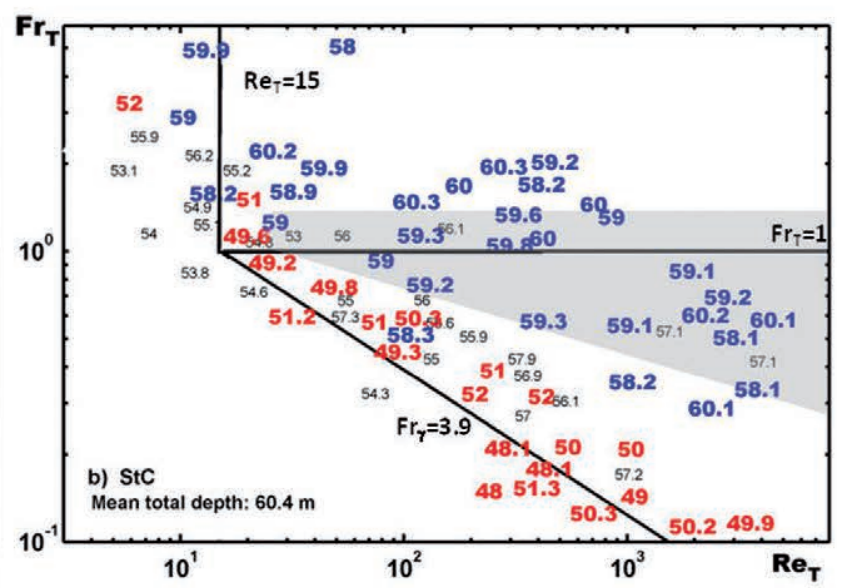

Fig. 11. - Hydrodynamic diagrams of $1 \mathrm{~m}$ segments within the turbid bottom boundary layer at (a) station StP and (b) station StC recorded in the evening of 19 and 20 June, respectively. 

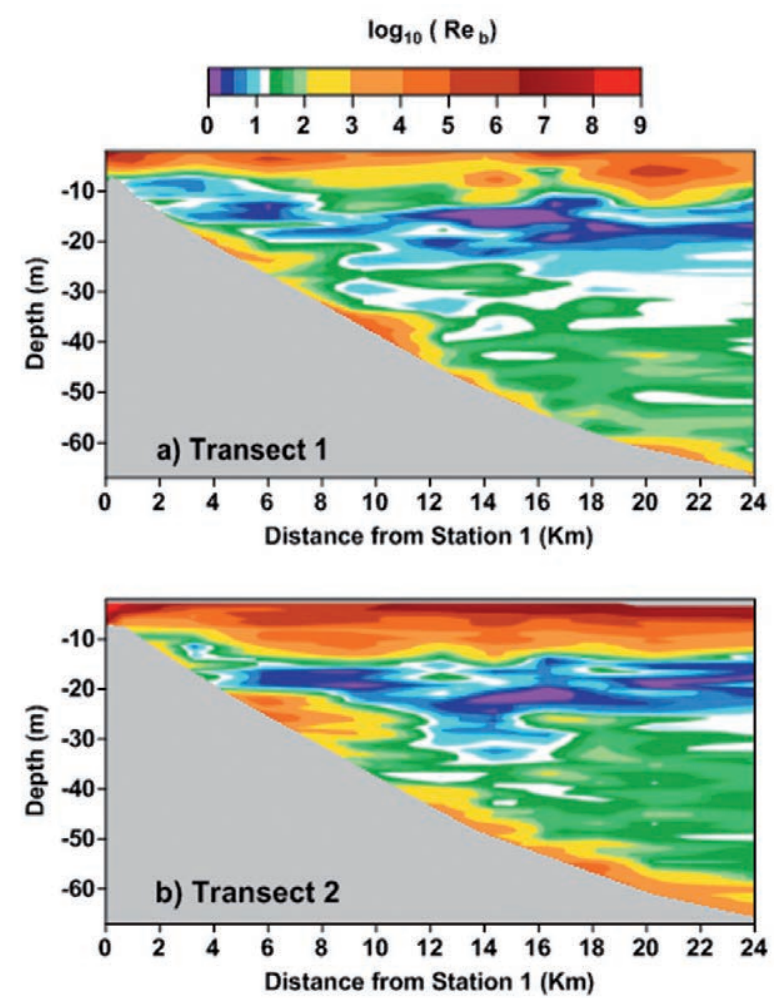

Fig. 12. - Contour plots of the buoyancy Reynolds number along transects (a) T1 and (b) T2.

mass transport. At station StP (Fig. 11a), in many of the segments at the interior of the BBL between 37 and 40 $\mathrm{m}$ depth and far from the bottom (green numbers) the mixing efficiency is $\gamma>0.15$ (within the shaded area).

As stated in the Material and Methods section, the state of the turbulence regarding the influence of the stratification can also be evaluated using the buoyancy Reynolds number, $R e_{b}$. Contour plots of $R e_{b}$ for both transects are presented in Figure 12. A comparison of Figure 12 with Figures 5 and 7 at the BBL shows that in general high dissipation rates correlate with low $N^{2}$, high turbidity and high $R e_{b}$. However, as expected, this is not the case in the region where the bottom depth is between 10 and $20 \mathrm{~m}$ because $N^{2}$ is very high, so the stratification does not allow fully developed turbulence, and $R e_{b}$ is low. Less understood is the fact that between 30 and $40 \mathrm{~m}$ depth in transect T2 $R e_{b}$ is low $\left(N^{2}\right.$ is relatively high and $\varepsilon$ is low; Fig $5 \mathrm{~b}, 7 \mathrm{~b}$ ) but turbidity is very high. This behaviour differs from that at all the other locations, where turbidity above the bottom is high and could indicate a different resuspension mechanism.

\section{DISCUSSION}

The temporal reversals of the main southwestward flow measured above the bottom before the campaign and its clockwise rotational behaviour, which can be seen in the Figure 3a, were also documented by other authors in the same region (Font et al. 1990, Salat et al.1992). Rippeth et al. (2002) studied the same region during the stratified season and also found two main periodic flow components within the diurnal and subinertial range, as presented in Figure $3 \mathrm{~b}$. The periodic behaviour of 24 hours was related by Rippeth et al. (2002) to the sea breeze regime of the area, which also dominated the wind field at the time when our campaign was carried out (Fig. 2). The near-inertial oscillations that they found were rotating clockwise like the data presented in Figure 3.

Salat et al. (1992) described how near-inertial currents decrease their intensity from the surface to the bottom, where inertial oscillations had velocities of about $10 \mathrm{~cm} / \mathrm{s}$, which is comparable to those observed during the 3 days prior to our campaign, as presented in the Results section. Rippeth et al. (2002) showed that oscillations generated after short episodes of high winds penetrate through the water column and last for 2 to 6 oscillations (between 1.5 and 5 days), as seen in Figure 3a. They documented a persistent phase shift close to $180^{\circ}$ between surface and near-bed velocities at both inertial and diurnal frequencies. Salat et al. (1992) also found phase shifts close to $170^{\circ}$ between surface and bottom $(100 \mathrm{~m})$ currents after high wind episodes of a few hours.

Because there were no relevant meteorological events between the time when the current meter was recovered and the time when we started the first transect (only a few hours later), we can assume that the main circulation in the area did not change. Therefore, at least during measurements along transect $\mathrm{T} 1$, diurnal onshore-offshore and sub-inertial oscillations were superimposed on a net southwest flow. Although this hypothesis is reasonable given the bibliographic references on the area and the data available, we cannot test it.

Following Rippeth et al. (2002), we can assume that main slopes of the isopycnals can be associated with the forced diurnal oscillation linked with the observed off/onshore wind pattern (Fig. 2). Figure 7 shows that at an intermediate depth of about $40 \mathrm{~m}$ the slopes of the isopycnals in the two transects are significantly different. This can be clearly seen from the $1028.3 \mathrm{~kg} / \mathrm{m}^{3}$ isopycnal highlighted in white, which descends as it approaches the coast in transect 2 (about $1 \mathrm{~m}$ per km) but not in transect 1 . Note also that in Figure $7 b$ the extension of the water column between the isopycnals of $1026 \mathrm{~kg} / \mathrm{m}^{3}$ and $1028.3 \mathrm{~kg} / \mathrm{m}^{3}$ increases considerably, moving from the deepest stations towards the coast. These differences could be explained by the excitation of a second baroclinic mode as a result of the two episodes of high wind after the recording along transect 1 (Fig. 2). Switching between the first and the second baroclinic modes has not been documented in this region but it has been observed in similar situations, as reported by Mackinnon and Gregg (2005) on the New England shelf. Shear induced at intermediate depths by a second baroclinic mode could be the origin of turbulence observed in transect 2 (Fig. 7b) in the mid-water 
column at the deeper stations, a region where the vertical distance between isopycnals decreases.

On the other hand, Tintoré et al. (1995) showed that quasi-inertial waves can be generated at the bottom of the mixing layer when a wave front propagates offshore after the passage of a storm. Salat et al. (1992) also mentioned that inertial waves provided the vertical shear needed for the deepening of the mixed layer that they observed. Accordingly, the deepening of the mixing layer observed from our data (Fig. 6) could also be explained by the existence of quasi-inertial internal waves.

As presented in the Results section, based on density and turbidity, a turbid bottom boundary layer was identified and the mean vertical extension of the BBL at stations along the studied transect with a depth larger than $20 \mathrm{~m}$ was found to be $7 \mathrm{~m}$, with a maximum value of $12 \mathrm{~m}$ at the deepest location. The law of the wall was observed to apply at most of the stations and for those deeper than $20 \mathrm{~m}$ its extension was $40 \%$ to $100 \%$ of the thickness of the BBL.

The analysis performed with the hydrodynamic diagram of two series of data recorded within the BBL at two different stations (Fig. 11) shows that vertical turbulent fluxes at the upper interface of the turbid BBL were negligible. Therefore, turbidity in the interior of the water column should be either horizontally advected offshore or vertically entrained from the bottom turbidity layer by large sporadic turbulent events which we did not capture with our measurements. A comparison of the turbidity contour plots for both transects (Fig. $5 \mathrm{c}, \mathrm{d})$ reveals a region of low turbidity at mid-water of the first transect which has become slightly more turbid in the second transect. This can be related to the differences in the background hydrodynamics, but the possible effects of bottom trawling resuspension at a depth of about $50 \mathrm{~m}$ during the day between the time when the two transects were recorded should also be taken into account (Demestre et al. 2008).

Sometimes energetic mixing events within the BBL but away from the bottom are observed, favouring the existence of a homogeneous turbidity layer (Fig. 10a). Well-developed turbulence $(\gamma>0.15)$ in the interior of the BBL was identified for 8 profiles out of the 15 measured at StP for 40 minutes (Fig. 11b). In general, it can be assumed that once particles are resuspended they are transported upwards by other mixing processes, increasing the vertical extension of the bottom turbidity layer. Several of such potential mechanisms were mentioned in the Introduction section, including critical reflection of internal waves.

Quasi-inertial waves, which can be generated at the bottom of the mixed layer, have a downward phase velocity and propagate at an angle $\theta$ with respect to the horizontal, according to the expression (Gill 1992) $\omega^{2}=N^{2} \sin ^{2} \theta+f^{2} \cos ^{2} \theta$. In the case of an oscillation of $16.6 \mathrm{~h}$ (Fig. 3b) and considering a background stratification of $N^{2} \sim 10^{-4} \mathrm{~s}^{-2}$ (Figs. 5a,b), the angle would be $\sim 0.06^{\circ}$, which is close to that of the bottom slope (Ta- ble 1). In such a case critical reflection is expected and after reflection the waves propagate along the slope. In the same area, Puig et al. (2001) identified the critical reflection of inertial waves as the cause of mixing enhancement above the seafloor and the formation of a bottom nepheloid layer. Dauxois et al. (2004), using laboratory studies without rotation, showed that for slightly sub-critical cases (i.e. $\theta / \theta_{c}=0.78$ ) large distortions of the isopycnals and overturning leading to unstable conditions were more important than for critical angles. For slightly super-critical cases (i.e. $\theta / \theta_{c}=1.14$ ), the density field did not fold up so abruptly and did not lead to overturning instability. Note that the angle of propagation of the inertial waves we have estimated is slightly smaller than the bottom slope of the shelf (Table 1), so near-critical reflection of internal waves could play an important role in boundary mixing, at least in some regions.

\section{ACKNOWLEDGEMENTS}

We are grateful to M. Demestre for allowing us to be on board the Garcia de Cid within the context of the VEDA Project and the EU RESPONSE (Q5RS-200200787) project and for facilitating the measurements. We are also very grateful to the editor and the anonymous reviewers, whose comments have helped to improve the first version of the paper. I. Lozovatsky and M Muñiz collaborated on the data analysis at an initial stage of this work. This paper was finished in accordance with the objectives of the project CGL2008-03608 funded by the Ministry of Science and Innovation of the Spanish Government and within the framework of the CLIMSEAS Project (FP7-PEOPLE-2009-IRSES N. 247512).

\section{REFERENCES}

Alford M., Pinkel A. 2000. Observations of Overturning in the Thermocline: The Context of Ocean Mixing. J. Phys. Oceanogr. 30: 805-832.

Cacchione D.A., Drake D.E. 1986. Nepheloid layers and internal waves over continental shelves and slopes. Geo-Mar. Let. 6: 147-152.

Cacchione D.A., Drake D.E., Losada M.A., Medina R. 1990. Bottom-boundary-layer measurements on the continental-shelf off the Ebro river, Spain. Mar. Geol. 95: 179-192.

Chant R.J. 2001. Evolution of near-inertial waves during an upwelling event on the New Jersey inner shelf. J. Phys. Oceanogr. 31: 746-764.

Dauxois T., Didier A.D., Falcon E. 2004. Observation of near-critical reflection of internal waves in stably stratified fluid. Phys. Fluid. 16:1936-1941

Davis AG., Soulby R.L., King H.L. 1988. A numerical model of the combined wave and current bottom boundary layer. J. Geophys. Res. C. 93: 491-508.

de Juan S., Demestre M., Thrush S. 2009. Defining ecological indicators of trawling disturbance when everywhere that can be fished is fished: A Mediterranean case study. Mar. Policy. 33: 472-478.

Demestre M., de Juan S., Sarto P., Ligas A. 2008. Seasonal closures as a measure of trawling effort control in two Mediterranean trawling grounds: Effects on epibenthic communities. Mar. Pollut. Bull. 56: 1765-1773.

Díaz J.I., Nelson C.H., Barber J.H., Giró S. 1990. Late pleisocente 
and holocene sedimentary facies on the Ebro continental-shelf. Mar. Geol. 95: 333-352.

Emery W.J., Thomson R.E. 2001. Data analysis methods in physical oceanography. Elsevier, 638 pp.

Eriksen C.C. 1985. Implications of ocean bottom reflection for internal wave spectra and mixing. J. Phys. Oceanogr. 15: $1145-1156$

Fernandes A.A., Chandramohan P., Nayak B.U. 1993. Observed current at Bombay high during a winter. Mahasagar 26: 95-104.

Fofonoff N.P., Millard Jr. R.C. 1983. Algorithms for computation of fundamental properties of seawater (1983), UNESCO Technical Papers in Marine Science. No. 44, Division of Marine Sciences. UNESCO, Place de Fontenoy, 75700 Paris.

Font J., Salat J., Tintoré J. 1988. Permanent features of the circulation in the Catalan Sea, Oceanol. Acta. 9: 51-57.

Font J., Salat J., Julià A. 1990. Marine circulation along the Ebro continental-margin. Mar. Geol. 95: 165-177.

Gargett A., Osborn T., Nasmyth P. 1984. Local isotropy and the decay of turbulence in a stratified fluid. J. Fluid Mech. 144: 231-280.

Garrett C., Gilbert.D. 1988. Estimates of vertical mixing by internal waves reflected off a sloping bottom. In: "Small Scale Turbulence and Mixing in the Ocean". Proc. 19th Liège Colloq. on Ocean Hydrodynamics, 405-424.

Garrett C. 1990. The role of secondary circulation in boundary mixing. J. Geophys. Res. C. 95: 3181-3188.

Gibson C.H. 1980. Fossil temperature, salinity, and vorticity turbulence in the ocean. In: Nihoul J.C.J. (ed.), Marine Turbulence, Elsevier Publishing Co., Amsterdam, pp. 221-257.

Gill A. 1982, Atmosphere-Ocean Dynamics. Academic Press, 662 pp.

Gonella J. 1972. A rotary component method for analysing meteorological and oceanographic vector time series. Deep-Sea Res. 19: 883-846.

Guillén J., Palanques A. 1997. A historical perspective of the morphological evolution in the lower Ebro River. Env. Geol. 30: 174-180.

Guillén J., Jiménez J.A., Palanques A., Gracia V., Puig P., SánchezArcilla, A. 2002. Sediment resuspension across a fetch-limited tideless inner shelf. Cont. Shelf Res. 22: 305-325.

Howarth, M.J., Souza A.J. 2005. Reynolds stress observations in continental shelf seas. Deep-Sea Res-II. 55: 1075-1086.

Imberger J., Boashash B. 1986. Application of the Wigner-Ville distribution to temperature gradient microstructure: A new technique to study small-scale variations. J. Phys. Oceanogr. 16: 1997-2012.

Ivey G.N., Nokes R.I. 1989. Mixing driven by the breaking of internal waves against sloping boundaries. J. Fluid Mech. 204 479-500.

Ivey G. N., Imberger J. 1991. On the nature of turbulence in a stratified fluid. 1. The energetics of mixing. J. Phys. Oceanogr. 21: 650-658.

Kundu P.J. 1990. Fluid Mechanics. Academic Press, 638 pp.

Lorke A., Umlauf L., Jonas T., Wüest A. 2002. Dynamics of Turbulence in Low-Speed Oscillating Bottom-Boundary Layers of Stratified Basins. Environ. Fluid Mech. 2: 291-313.

Lorke A., Peeters F., Wuest A. 2005. Shear-induced convective mixing in bottom boundary layers on slopes. Limnol. Oceanogr. 50: 1612-1619.

Lozovatsky I., Roget E., Fernando H.J.S., Figueroa M., Shapovalov S. 2006. Sheared turbulence in low-speed oscillating bottom. boundaary layers of stratified basins. Deep-Sea Res. I 53 $87-407$.

MacKinnon J.A., Gregg M.C. 2005. Near-inertial waves on the New England shelf: The role of evolving stratification, turbulent dissipation, and bottom drag. J. Phys. Oceanogr. 35: 2408-2424

McPhee-Shaw E.E., Kunze E. 2002. Boundary layer intrusions from a sloping bottom: A mechanism for generating intermediate nepheloid layers' J. Geophys. Res. 107: 3050.

Millot C., Crepon M. 1981. Inertial oscillations on the continentalshelf of the gulf of Lions - observations and theory. J. Phys. Oceanogr. 11: 639-657.

Moum J.N., Perlin A., Klymak J.M., Levine M.D., Boyd T., Kosro P.M. 2004. Convectively driven mixing in the bottom boundary layer. J. Phys. Oceanogr. 34: 2189-2202.

Osborn T.R. 1980. Estimates of local rate of vertical diffusion from dissipation measurements. J. Phys. Oceanogr. 10: 83-89.
Palanques A., Drake D.E. 1990. Distribution and dispersal of suspended particulate matter on the Ebro continental-shelf, northwestern Mediterranean-sea. Mar. Geol. 95: 193-206.

Palanques A., Puig P., Guillén J., Jiménez J., Gracia V., SánchezArcilla A., Madsen O. 2002. Near-bottom suspended sediment fluxes on the microtidal low-energy Ebro continental shelf (NW Mediterranean). Cont. Shelf Res. 22: 285-303.

Panchev S., Kesich,D. 1969. Energy spectrum of isotropic turbulence at large wavenumbers. Comptes rendus de l'Académie Bulgare des Sciences. 22: 627-630.

Perlin A., Moum J.N., Klymak J.M., Levine M.D., Boyd T. Kosro P.M. 2005. A modified law-of-the-wall applied to oceanic bottom boundary layers. J. Geophys. Res. 110: C10S10.

Phillips O.M., Shyu J.H., Salmun H. 1986. An experiment on boundary mixing - mean circulation and transport rates. J. Fluid Mech. 173: 473-499.

Piera J., Roget E., Catalan J. 2002. Turbulent patch identification in microstructure profiles: a method based on wavelet denoising and Thorpe displacement analysis. J. Atmos. Ocean. Tech. 19: 1390-1402.

Prandke H., Stips A. 1998. Test measurements with an operational microstructure turbulence profiler: detection limit of dissipations rates. Aquat. Sci. 60: 191-209.

Prandke H. 2005. Microstructure sensors. In: Marine Turbulence: Theories, Observations and Models, edited by Baumert $\mathrm{H}$ Z., Simpson J.H., Sundermann J. Cambridge Univ. Press, pp.101-109.

Puig P., Palanques A., Guillén J. 2001. Near-bottom suspended sediment variability caused by storms and near-inertial internal waves on the Ebro mid continental shelf (NW Mediterranean). Mar. Geol. 178: 81-93.

Roget E., Lozovatsky I., Sánchez X., Figueroa. M. 2006. Microstructure measurements in natural waters: Methodology and applications. Prog. Oceanogr. 70: 126-148.

Rippeth T.P., Simpson J.H., Player R.J., Garcia M. 2002. Current oscillations in the diurnal-inertial band on the Catalonian shelf in spring. Cont. Shelf Res. 22: 247-265.

Salat J., Tintoré J., Font J., Wang D. P., Vieira M. 1992. Nearinertial motion on the shelf-slope front off northeast Spain. $J$. Geophys. Res. 97: 7277-7281.

Sánchez X., Roget E. 2006. Microstructure measurements and heat flux calculations of a triple-diffusive process in a lake within the diffusive layer convection regime. Deep-Sea Res-I 53: 387-407.

Soloviev A., Klinger, B. 2001. Open Ocean Convection. In: Encyclopedia of Ocean Sciences, Vol.4 Academic Press, pp. 2015-2022.

Stansfield K. Garrett C., Dewey R. 2001. The probability distribution of the Thorpe displacement within overturns in Juan de Fuca Strait. J. Phys. Oceanogr. 31: 3421-3434.

Staquet C., Sommeria J. 2002. Internal gravity waves: From instabilities to turbulence. Annu. Rev. Fluid Mech. 34: 559-593.

Stillinger, D.C., Hellnad, K.N., Van Atta, C.W., 1983. Experiments on the transition of homogeneous turbulence to internal waves in a stratified fluid. J. Fluid Mech. 131: 91-122.

Thorpe S.A. 1977. Turbulence and mixing in a Scottish Loch. Philos. T. R. Soc. Lon. A 286: 125-181.

Thorpe S.A. 1987. On the reflection of a train of finite amplitude internal waves from a uniform slope. J. Fluid Mech. 78: 279-302.

Thorpe S.A. 1997. On the interaction of internal waves reflecting from slopes. J. Phys. Oceanogr. 27: 2072-2078.

Thorpe, S.A. 2004. Recent developments in the study of ocean turbulence. Annu. Rev. Earth Planet Sci. 32: 91-109

Tintoré J., Wang D.P., García E., Viudez A. 1995. Near-inertial motions in the coastal ocean. J. Marine Syst. 6, 301-312.

van Haren J.J.M., Maas L.R.M. 1987. Temperature and current fluctuations due to tidal advection of a front. Neth. J. Sea Res. 21: 79-94.

Wells M., Cenedese C., Caulfield C.P. 2010. The relationship between flux coefficient and entrainment ratio in density currents. J. Phys. Oceanogr. 40: 2713-2727.

Wolk F., Yamazaki H., Seuront L., Lueck R.G. 2002. A new freefall profiler for measuring biophysical microstructure. J. Atmos. Ocean. Tech. 19: 780-793.

Received March 6, 2011. Accepted November 21, 2011.

Published online August 3, 2012. 
